\title{
Translational and Clinical Pharmacology: Note from the new Editor-in-Chief
}

\author{
Sang-Goo Shin* \\ Emeritus Professor \\ Department of Clinical Pharmacology and Therapeutics, Seoul National University College of Medicine, Seoul, Korea \\ ${ }^{\star}$ Correspondence: S. G. Shin; Tel: +82-10-3783-8286, E-mail: capmed01@snu.ac.kr
}

Check for updates

pISSN: 2289-0882

elSSN: 2383-5427

It is a great honor and a privilege for me to assume the role of Editor-in-Chief of Translational and Clinical Pharmacology (TCP) through the decision of the Board directors of the Korean Society for Clinical Pharmacology and Therapeutics (KSCPT).

I will follow in the footsteps of Professor Jung-Sang Lee, the $1^{\text {st }}$ Editor-in-Chief of Journal of Korean Society for Clinical Pharmacology and Therapeutics. A special thanks go to the outgoing Editor-in-Chief, Professor Dong-Seok Yim at Catholic University College of Medicine. Professor Yim has demonstrated tremendous leadership for the last five years to achieve significant milestones, including the launch of the English version of the journal in response to globalization.

The Korean Society for Clinical Pharmacology and Therapeutics (KSCPT) was established in 1992. Just one year after, the official journal of the Journal of KSCPT (JKSCPT) published, and the landmark Volume 1. issue was printed in Spring, 1993. Since then, JKSCPT was published as a biannual journal, reaching Volume 21 in 2013. In 2014, in response to globalization and to the thirst of an upgrade in quality, the journal selected English as the official language, and the issue has been increased to a quarterly publication. Thanks to the effort and devotion of Prof. Dong-Seok Yim, previous Editor-in-Chief, and special thanks to the endless support from internationally well-known Clinical Pharmacologists, Dr. Atkinson and Dr. Holford, it only took five years to settle as a quarterly published, English journal in the Translational Research and Clinical Pharmacology field.
The board members of KSCPT have reorganized a new editorial team for TCP in March this year. I appreciate that this is a clear message which reflects the desire of upgrading TCP to the next level. To meet this need and desire, we will systematically reinforce the editorial team, which will lead to improvement in the content quality and settlement of a robust review system. For a more intimate and tighter working environment with the Editor-in-Chief, we will nominate executive editor as deputy Editor-in-Chief. Also, we will classify 'Clinical Pharmacology and Translational Clinical Research' into six categories, while associate editors will be appointed for each part, to the boost up the efficiency of the original article review process and tutorial/ review article selection process. The scope of the journal will be expanded to the translational clinical research area, which will broaden the previous area of interest of clinical pharmacology and clinical trials. This will permit clinical researchers from various medical fields to submit many research articles, which will contribute to the quality improvement of TCP.

In conclusion, I am excited to work together with the talented deputy editor-in-chief, associate editors and editorial board members to make our goal possible. Most importantly, I will seek your continuous interest, support, and commitment. I look forward to working with you in your role as a submitting author, reviewer or editor to receive high-quality papers and to bring about new achievements for TCP. 